This is the accepted version of this paper. The version of record can be accessed at https://doi.org/10.1680/jmapl.20.00014 


\title{
Realising Project Benefits in the public sector: Project Sponsor's perspective
}

\author{
Alex Opoku ${ }^{1}$, Alexander Tallon ${ }^{2}$, Ka Leung Lok ${ }^{3}$, Charles X. L. Chen ${ }^{4}$ and Tariq Umar ${ }^{5}$ \\ 1,2Bartlett School of Construction and Project Management, University College London, UK \\ ${ }^{3,4}$ Chongqing Business \& Technology University, National Research Base of Intelligent \\ Manufacturing Service, Chongqing, China \\ ${ }^{5}$ College of Engineering, A'Sharqiyah University, Ibra, Oman
}

\begin{abstract}
Managing the realisation of project benefits in public sector organizations is fundamental in ensuring value is added by projects and programmes. Project sponsors are charged with championing projects in organizations to create value in line with organizational strategy. This study examines how the sponsor defines project benefits, aligns them with organizational strategy and ensures they are delivered. The paper presents the results of a Case study involving a major public sector organization in the UK using qualitative data collection through interview with 14 sponsors across the business. It also confirms that sponsors must be empowered and held to account in order to create meaningful value for an organization. No business organization can survive without creating value for customers, and therefore project sponsorship is an essential function of organizations. The findings from this research will enable the case study organization and similar public sector organizations to become a more 'Intelligent Client' and ensure that all investment is aligned with the wider organizational strategy. It contributes to knowledge in the broader research base by building a clearer understanding of how public sector organizations employ the sponsor function to ensure that projects align well with business strategy
\end{abstract}

Keywords: Project management, Business, Infrastructure planning, public service engineering 


\section{$1 \quad 1$ Introduction}

2 The successful delivery and realisation of project benefits of public sector organizations are at

3 the heart of the project sponsor's role and responsibilities (Opoku and Tallon, 2019).

4 Organizations define strategies that chart how they compete for business and deliver value for

5 customers, using their business model to facilitate this (DaSilva and Trkman, 2014). The

6 strategy development process of an organization can take a prescriptive or emergent approach,

7 and this will affect the way in which the organization is able to respond to challenges and

8 opportunities that it faces (Lynch, 2006). The chosen strategy that an organization follows must

9 align with the market that it is competing in, and whether it wants to lead in product innovation or

10 cost (Porter, 1980). Depending on this decision an organization will complete projects, which

11 are unique endeavours undertaken in order to create value, in line with their strategy. Research

12 has identified that there are a wide range of change activities and projects needed by

13 organizations, each requiring a unique approach to delivery (Morris and Pinto, 2004).

14 Organizations need to ensure that completed projects deliver benefits aligning to their strategy.

15 Benefits management processes have been proposed in order to align project and strategic

16 objectives; the aim of these processes is to ensure that value is created effectively (Melton et

17 al., 2011). If value is not created effectively shareholders may dismiss and replace a firm's

18 board, or a firm may be subject to a hostile takeover. Privatisation is a possible outcome for

19 public bodies that fail to create cost effective value for stakeholders. In each of these scenarios

20 projects are critical in ensuring organizational survival.

22 Organizations are not always successful at delivering their strategies; and Pellegrinell and 23 Bowman (1994) analysed this and identified a common reason: senior management define 24 organizational strategy but leave junior staff to deliver change initiatives (projects) that align to 25 the strategy. In order to ensure that projects deliver benefits that align with strategy, some 26 organizations have invested in project sponsorship. The role of the sponsor has been 27 researched and defined by various authors, including Bryde (2008) who identified the role of the 28 sponsor as; to act as the client's representative for the project. When project benefits are 
defined and aligned to organizational strategy differently in each business area within the organization, it is likely to give rise to varying success of meeting the organizational objectives. The case study organization in this research has a sponsorship function to align investment with the core business strategy and ensure that an internal client role is present to champion every project. Breese et al. (2020) argue that, understanding the role of the project sponsor and benefits realisation is critical to project success and should be investigated. This research provides a theoretical understanding of the issues faced when large public sector organization implements the sponsor role. The next section (Section 2) presents a review of literature on benefit realisation and project sponsor role whiles section 3 describes the adopted research methodology. The analysis of the results of the study is presented in section 4 , and section 5 discusses the research findings against literature findings. The conclusion in Section 6 highlights the implications of the research and some limitations.

\section{Literature Review}

Meredith and Zwikae (2020) believe that most current projects fail to achieve the strategic benefits which are the reason for commissioning projects in the first place. Strategy is the direction that a firm choses to follow in order to create value for customers and gain competitive advantage whilst doing so. Porter's (2001) second principle clearly links strategy to benefits that a firm deliver, a fundamental link that this research explores. However, the fifth principle is important to consider because it demonstrates how strategy links all parts of a firm together, and this is important to remember when considering the role of the sponsor. This principle is confirmed by other scholars and has been enhanced by DaSilva and Trkman (2014) who introduced the concept of dynamic capabilities as linking a firm's business model and strategy: defining all three key terms as different time scale perspectives for a firm. Strategy development is often completed by firms and then used to define their business model. The strategy definition process is normally completed in a prescriptive or emergent manner, depending on the organization involved (Lynch, 2006). However, the process can be completed in a manner that 
57 Emergent strategy development. Prescriptive strategy development is a classical method that organizations employ, involving senior managers determining priorities and imposing a business model and capabilities on the firm in order to meet the defined goals (Lynch, 2006). Mintzberg (2003) considers prescriptive strategy development to be an inflexible and non-linear process that is not adaptive to changes in markets. Emergent strategy development has become more common and is defined as bottom up and people-led strategy definition within an organization; often it involves staffs who are not senior managers and facilitates flexible changes in dynamic markets (Moore, 2006). It is sometimes defined as being without a-priori intentions (Burnes, 2004) and this can make it a challenge to incorporate in large organizations because of the long-time scales require to change course. Wherever the strategy development process of an organization is on the spectrum between prescriptive and emergent; it often has to be delivered and realised through planned and prescriptive change initiatives called projects. At the project level, the project owner is usually interested in exploiting the business benefits of the project by joining the project portfolio management team (Hyvaria, 2014).

\subsection{Defining the role of the Sponsor}

As the desire by the Project Management sector to explore issues affecting project success continues to gain coverage, the role of the Project Sponsor in realising project benefits is more important than ever (Turner, 2017). Project management has often focused on delivering a project to the correct cost, quality and schedule (Winch, 2010); it does not focus on ensuring that the correct project is delivered by an organization in order to deliver its strategy. This is where the role of the sponsor has been developed to ensure that an organization completes the right projects. In the prescriptive model of change management, senior management develop and write organizational strategy (Lynch, 2006). This is implemented by client functions within the business, a role that can be considered equivalent and synonymous with that of a sponsor (Pellegrinelli and Bowman, 1994). Bryde (2008:801) defines the role of the sponsor as the critical risk taker for a project "responsible for activities that span across the whole of the project lifecycle in a study that reviewed several definitions from scholars and professional industry bodies. This includes the framework of activities identified in 
[Insert Table. Typically, a project sponsor owns the project's business case and takes the risk; the sponsor should act as the champion, leader and facilitator who understand the project and the vision to achieve the project benefits (APM, 2018).

\section{[Insert Table 1 here]}

Wright (1997) described the sponsor role using the term Project Champion and the term Owner has also been used (Winch and Leiringer, 2016). Therefore, reviews of the role and responsibilities of the sponsor must be cognisant of the plethora of terminology that relates to the role. The key role for the sponsor is to create projects that deliver changes to meet the business's strategy; however, the role is then to allow others to manage and deliver the projects effectively, whilst maintaining an oversight role (Sense, 2013). The sponsor must take ownership of the project after the delivery is complete to measure the effectiveness of the scheme at meeting the defined objectives. However, a challenge for the role of sponsor is the principal agent problem. Communication is fundamental to the role; however, hidden action and asymmetry of information could easily occur between senior management and the sponsor, or between the sponsor and stakeholders and project management professionals (Turner and Müller, 2004). Some organizations have tried to address these challenges by using lesson learnt systems, technology and frequent reporting, but these have disadvantages including cost, administration effort and reliability (Opoku and Tallon, 2019).

The importance of having a project sponsor has been recognised by the private sector as well. Analysis by KPMG (2017:18) identified it as the "difference between success and failure" of a project. This report identified key roles for the sponsor and these are in line with those that other academics have suggested, whilst adding a stakeholder management role as: "leading the project selection process, defining requirements and benefits that encompass the vision in measureable deliverables, linking projects to organizational strategy, liaising with stakeholders and advocating the project" (KPMG, 2017:20). In situations where the project sponsor may not fully understand the project risk because of a passive involvement at the project initiation stage (project front-end), it is essential that the project sponsor meets the project initiator to set, clarify, and align projects benefits and expectations (Steyn, 2019). According to the Project 
116 Management Institute (2018), an actively engaged project sponsor is an important project driver

117 towards the realisation of the business goals set out at the beginning of the project.

\section{$118 \quad 2.2$ Project success factors}

119 The success of a project can be measured in different ways: success criteria are metrics that an organization defines to judge whether an initiative or the organization itself has been successful in meeting its goals (Opoku and Tallon, 2019). It can be financial, rates or performances related but are fixed with a boundary to pass in order to demonstrate success and are commonly linked for projects to the iron triangle of cost, time and quality (Cooke-Davies, 2002; Winch, 2010). Success factors are similar; the presence of them indicates that an initiative is likely to succeed in meeting an organization's objectives. A successful project in the public sector is determined by the delivery of the project within budget, meeting end-user's expectations and completing on time (Songer and Molenaar, 1997). However, Tabish and Jha (2011) identified four success factors for public sector projects including compliance and awareness with rules and regulations, clarity of scope and pre-project planning, effective partnering among project participants; and external monitoring and control. The project sponsor/owner has specific tasks in projects and Winch and Leiringer (2016) develop a framework of owner project capabilities as presented in [Insert Table. However, the Sponsor role is to ensure the proposal meet requirements in respect of definition, governance, execution and benefits realisation.

[Insert Table 2 here]

\section{$136 \quad 2.3$ Project benefit realisation}

137 Benefits are the incremental improvements that organizations create to add value (Zwikael and Smyrk, 2011); in private business this is shareholder value, whereas in the public sector it is often social benefit. Benefits can be tangible or intangible and are broadly defined in the project sector as "a measurable advantage owned by a group of stakeholders incurred by changing the current state through project management mechanisms" (Badewi, 2016:763). Benefits are used by organizations to fill the gap in value between what is present today and what is required to deliver the strategy (Kaplan and Norton, 2008). Figure 1, illustrates how organizations use 
144 outputs of projects to create outcomes, and subsequently benefits, all of which deliver new 145 value (Serra and Kunc, 2015).

146

Figure 1: Creating desired value by investing in benefits (adapted from Serra and Kunc, 2015)

The importance of benefits in relation to projects is clear and the management of benefits is therefore crucial to the success of projects. Benefits management is defined as "initiating, planning, organising, executing, controlling, transitioning and supporting of change in the organization and its consequences as incurred by project management mechanisms to realise predefined project benefits" (Badewi, 2016:763). Analysis of the effectiveness of an organization's benefits management processes can be completed by comparing it to four competences collated by Ashurst et al. (2008); planning, delivering, reviewing and exploiting.

158 Benefits management processes must operate alongside project management to deliver shareholder value or social benefits. Benefits management has been identified as a critical project success factor, especially when benefits management processes are embedded in corporate governance (Serra and Kunc, 2015).

162

\section{Research Design}

164 The study adopts interpretivist research philosophy since research into the application of project

165 sponsorship activities is difficult to complete quantitatively despite the theoretical frameworks for 166 responsibilities of the sponsor. Therefore, a qualitative research method has been chosen to 167 help understand current practice towards effective benefits realisation and analyse the activities 168 that sponsors complete in the case study organization. The case study involves a public sector 169 organization formed in the early 2000s with four business areas supported by professional 170 service functions. A qualitative method of research acknowledges the multiple realities that may 171 be observed throughout the process (Quinlan et al., 2014). Primary data collection is through 
semi-structured interviews with sponsors in three business areas within the case study organization; each business area in the organization has unique projects, challenges and stakeholders. The number of interviewees required before reaching saturation was determined to be 12 following analysis by Guest (2006); however, this has been challenged by other scholars including Francis et al. (2014) who proposed that 14 individuals were required. The interviews which lasted 30-40 minutes each enhanced the understanding of the processes that sponsors follow, and also helped to validate the theoretical knowledge in the field. The interview data was analysed using qualitative content analysis. This is a detailed process, initially involving extensive immersion in the interview data, followed by a process of coding and grouping responses by themes (Fellows and Liu, 2003).

\section{Results and Analysis}

The interview sample consists of 14 sponsors from three different business areas of the organization. This provides a comparison of how projects and benefits are defined, aligned and realised across the organization. The interviewees are involved greatly with projects and less responsibility for management; this is to ensure that they are focused on projects and value creation within the business. A profile of the interviewees is presented in Table 3. The Principal Sponsor acts as an internal client, supporting the Lead Sponsor to sponsor the delivery of large, long-term investment programmes. The sponsor is however responsible for the development, monitoring and benefit realisation of a portfolio of projects or programmes sponsored within the Investment Programme.

[Insert Table 3 here]

\subsection{Understanding the organizational strategy}

There were multiple ways identified by sponsors for how projects are aligned with strategy. A key document identified to assist with this task is the business case, which records monetised scheme benefits and the links to strategy. Some sponsors focused more on the requirements 
200 gathering and review processes in collaboration with other teams in order to ensure that it is

201 aligned with the strategy of schemes. The results show that sponsors take the responsibility of

202 defining scheme benefits seriously by using business-wide metrics and aligned with weighted

203 measurable needs as appropriate for the business and customer's requirements:

204 "I weight some priorities higher than others in line with strategy" (Interviewee I).

205 However, whilst recognising the importance of aligning benefits with strategic priorities, some

206 interviewees discussed how it is more common to align requirements instead of benefits with

207 strategy. Another interviewee stressed the challenges of working in a political organization:

208 "It can be difficult to define and align benefits (with strategy) when the Government define 209 scheme requirements" (Interviewee C).

210 The sponsor has the responsibility of establishing project strategy, however, several sponsors

211 found this task challenging to complete for various reasons: these included third party funding

212 limiting the influence the sponsor can have on the scheme, as well as the highly political nature

213 of the work when negotiating priorities of organization and the other stakeholders. However, an

214 interviewee working on a third party funded project emphasised how the sponsors had created a

215 'strap line' which embodies their strategy, demonstrating that even in the intense political

216 environment sponsors can complete this task. How the benefits realisation phase is completed

217 appears to depend on the type of scheme. Standardised metrics are used by some projects to

218 collect realisation data in line with the business case that justified the scheme. Interviewee ' $M$ '

219 commented that;

220 "More studies are completed if the scheme is larger, and in some cases programme wide 221 realisation is expected and completed, partly to justify future investment".

222 Because of the long timescales of projects some sponsors identified that staff turnover impacted 223 their ability to effectively complete benefits realisation. This applied not only to sponsors

224 changing roles but also staff moving on from the wider project team. However, sponsors

225 indicated that team wide tacit knowledge and institutional memory is very high within some parts

226 of the organization. This is unique to parts of the organization with high long-term staff retention. 


\section{$227 \quad 4.2$ Defining project success criteria}

228 A crucial part of the project definition and alignment process is to establish success criteria.

229 Sponsors completed this using standardised metrics within their business area, like journey time reliability. The study shows that sponsors are accountable for the definition, management and review of success criteria throughout a project's life-cycle; ensuring that the metrics used link to the organizational strategy. The metrics used to define project success were broadly in line with the traditionally defined hard success criteria that form the iron triangle. This was embedded in the business by the requirements management processes and board reviews utilising standardised metrics. However, there is also a focus on more holistic and long-term metrics like value and success factors, using the term 'benefits' to define their project success indicators. Some sponsors admitted only collecting the data required to either update their business case or pass a stage gate review, as required by internal processes. Interviewee ' $\mathrm{N}$ ' commented that; "Benefits are often bespoke and scheme specific to ensure they are binary, clear and repeatable after a scheme's implementation" (Interviewee N).

241 The process to collect and define benefits was identified to be the responsibility of the sponsor;

242 but data may be collected by internal or external parties, either as part of business as usual or 243 on an ad-hoc basis.

\section{$245 \quad 4.3$ Aligning project benefits with strategy}

246 Multiple tools are used by the organization to define and manage benefits and ensure they align 247 with strategies. These include quantitative and qualitative methods such as a business case, 248 project requirements statement and benefits management plan etc. The benefits management 249 plan was identified as the document aligning benefits to strategy best, but also as being "very complex, leading to caring about cost, quality and time on a day to day basis" (Interviewee H).

251 The metrics collected to define and assess project benefits were frequently discussed to be 252 quantitative, standardised and linked to organizational strategy, like success criteria.

253 Interviewees didn't believe there is a standardised process and felt unsupported due to working 254 in a small team as stated by interviewee ' $\mathrm{H}$ ';

255 "There is a very unclear process to defining and aligning benefits (in respect to strategy)". 
256 The approach to benefits definition was identified as defined at programme level and not organization or business wide. One interviewee stated that benefits are "mainly valuable later"

258 (Interviewee M). This comment indicates the process isn't successful in their business area, and 259 if the planning competence is not effectively delivered it will be difficult for the organization to 260 deliver later competences. The process to select projects which best meet organizational needs when limited funds are available was investigated. Boards often decide how to proceed, and the decision can be driven by political influence as well as by comparing project benefits. Interviewee ' $A$ ' referred to a workshop prioritisation process and assessment using criteria defined at programme level. Corporate sponsors identified a Multi-Criteria Assessment framework used to define and assess projects and options. Sponsors agreed that qualitative comparisons lead to better, customer-focused decisions.

\subsection{The sponsor's role in benefits realisation}

269 Sponsor's role during the initiation project phase is to define clear goals for projects, in some cases using processes like benefits mapping. Sponsors ensure projects realise benefits by maintaining regular communication, defining clear aims and requirements and "ensuring the problem is fully understood prior to identifying solutions" (Interviewee B). There is an important role for sponsors to ensure that benefits are realised throughout the lifecycle of the project; stage gate reviews, project boards and the change control process were identified as critical to review benefits. Interviewee 'J' argued that; "Stakeholders propose changes and the role of the sponsor is to review the change in line with the impact it may have on the benefits of the scheme" (Interviewee J).

279 One sponsor described his role as an "active team player managing stakeholders and understanding issues" (Interviewee N) thus enabling him to protect scheme benefits. Some sponsors commented that the quick move to new projects after delivery means benefits realisation doesn't get completed fully.

283 Sponsors proactively take responsibility for monitoring project outcomes during construction and post construction, comparing the results with pre-scheme data on benefit realisation. Moreover, 
there is an internal benefits support team as part of the Project Management Office to provide guidance, and on some projects "contractor benefit analysis is written into the project contract" (Interviewee M). The timescale after which benefits are realised can vary depending on the nature and the project's relationship with other interlinked and non-linear programme investments. In some cases data is not available for at least 3 years after project completion, and for large scale projects, 10 year frameworks may be more realistic if wider scheme effects are to be included. The benefits realisation phase also demonstrated a principal agent problem where there is the tendency by sponsors to only report and amplify good/positive news. This is mostly done in order to secure further programme funding for future schemes. In terms of how information/data is collected during benefits realisation, it was noted that the benefits process contrasts with the lessons learnt process, which is managed using a centrally recorded portal. Some local project reporting tools existed in some parts of the business, but did not feed into a central system. The project close out report was the only compulsory document identified by sponsors to record this information in a qualitative manner, but this doesn't enable the business to map project completion to organizational objectives. For example, interviewee 'M' commented that; "Data on benefits from most projects is not centrally captured, but likely to be saved on local team shared drives".

303 Again, the business tends to focus mainly on the delivery of outputs and not benefits, as noted by interviewee ' $G$ '; "benefits realisation is not championed by senior managers, and therefore it doesn't happen". Most sponsors understood their role in collecting baseline data, but some identified how data can't always be requested ad-hoc for a scheme and internal annual surveys

307 have to be used. Reviewing lessons learnt from other schemes was considered important when 308 sponsors are defining benefits.

309

\section{Discussions}

311 A firm's strategy and the strategy development process define the need for firms to complete

312 projects and change initiatives. The strategy development process of the case study 
313 organization has been identified as prescriptive. Sponsors have a clear understanding of

314 organizational strategy and use multiple tools to align projects with strategies. It has been

315 confirmed that sponsors are involved in defining project success criteria (Bryde, 2008), but they

316 find it harder to implement these when third party funding is supporting a project. However,

317 corporate sponsors have less responsibility to define success criteria because other project

318 teams set clear objectives. The study shows that business areas in the organization do have

319 processes to manage project benefits realisation. The case study results demonstrated that,

320 some processes are discharged in a mature fashion, including the first two competences of

321 benefits management (planning, delivering, reviewing and exploiting; Ashurst et al., 2008)

322 compared to the third and fourth competence. The sponsor has a role including the strategic

323 capabilities of owners. The benefits management processes have local variations and aren't

324 centralised. Some variations are effective at managing benefits, and some internal project

325 management methodology documentation is best suited to larger projects. To improve benefits

326 management processes, the organization needs to recognise its value and harmonise

327 processes. The case study organization has an effective sponsorship function that links the

328 responsibilities to the strategic capabilities of strong owners. The project sponsor's role is to

329 define, manage and deliver project benefits in line with an organization's strategy. Project

330 sponsors must be empowered and held to account in order to create meaningful value for an

331 organization. The way in which projects and their benefits are defined and aligned with respect

332 to organizational strategy was expected to be different in each business area within the

333 organization. This is likely to give rise to varying success of meeting organizational objectives.

334 Analysis of project benefits management enables the business to understand opportunities for

335 improvement and provide a theoretical understanding of the issues faced when large public

336 sector organizations implement the sponsor's role.

337

338 


\section{Conclusions}

340 Benefits realisation throughout the life-cycle of in-flight projects was also considered and

341 benefits were mainly found to be managed and protected using the change control and gate

342 review processes, which are mandatory across all business areas in the organization. Other

343 formal documentations and reviews required by internal project management methodology and

344 assurance reviews, led to benefits management tasks being completed. For projects post-

345 completion, the benefits realisation process was managed in different ways depending on

346 business area. Depending on the details available from a project's definition phase, sponsors

347 generally complete benefits realisation, but this depended on time availability. The methods that

348 sponsors use to define and align project benefits were uncovered to include internal project

349 management methodology documentation and a project overview plan for smaller projects. The

350 benefits alignment process varied according to business area but aimed to link to both the

351 organization's strategy and local business plans.

352 More success at completing benefits realisation was observed when future programme funding

353 relied upon data from current schemes. Several methods of managing benefits were observed

354 across the business and several were identified; the benefits management culture in the

355 organization was found to be well embedded, supported by standardised documentation. The

356 sponsors who looked after fewer larger projects seemed to place more emphasis on following

357 the processes required, mainly because they had more time to do so at each project stage

358 compared to the time available for sponsors looking after many small projects concurrently.

359 However, to improve the quality of benefits management, a formal benefits realisation for each project should be adopted. Senior management should create a culture that focuses on value creation by ensuring project delivery success criteria observe the wider benefits. This research validates the responsibilities of sponsors as proposed by Bryde (2008; it confirms the effectiveness of the sponsorship function at case study organization, and also link the responsibilities to the strategic capabilities of strong owners (Winch and Leiringer, 2016). This research contributes knowledge to the broader research base by building a clearer understanding of how project base organizations employ the sponsor's function to ensure that projects align with strategy. The research findings are useful to both the case study organization 
and other similar public sector organizations including Government departments and local

authorities. However, the use of one organization for the study is a limitation of this research affecting any generalisation of the results. Even though the research is based on one case study organization, the results are applicable to other large client organizations, government departments and local authorities in an attempt to improve their creation of value.

\section{Acknowledgement}

The authors thank the editorial team of the ICE's Journal of Management Procurement and Law (JMPL) for selecting the original paper, "The Role of Project Sponsors in Defining and Realising JMPL. The original paper was submitted to the 35th Annual ARCOM Conference in Leeds, 2019.

\section{References}

APM (2018), Sponsoring Change: A guide to the Governance Aspect of project sponsorship, 2nd Edition, Association for Project Management (APM) Governance Specific Interest Group: London

Ashurst, C., Doherty, N. F., and Peppard, J. (2008), Improving the impact of IT development projects: the benefits realization capability model, European Journal of Information Systems, 17(4), 352-370.

Badewi, A. (2016), The impact of project management (PM) and benefits management (BM) practices on project success: Towards developing a project benefits governance framework. International Journal of Project Management, 34(4), 761-778.

Breese, R., Couch, O. and Turner, D. (2020), The project sponsor role and benefits realisation: More than 'just doing the day job, International Journal of Project Management, 38(1), 17-26

Bryde, D. (2008), Perceptions of the impact of project sponsorship practices on project success, International Journal of Project Management, 26(8), 800-809.

Burnes, B. (2004), Emergent Change and Planned Change - Competitors or Allies? International Journal of Operations and Production Management, 24(9): 886-902.

Cooke-Davies, T. (2002), The "real" success factors on projects, International Journal of Project Management, 20(3), 185-190.

DaSilva, C. M., and Trkman, P. (2014), Business model: what it is and what it is not. Long range planning, 47(6), 379-389.

Fellows, R. F., and Liu, A. M. (2003), Research methods for construction. 2nd ed. Oxford: Blackwell Science.

Francis, J. J., Johnston, M., Robertson, C., Glidewell, L., Entwistle, V., Eccles, M. P., and Grimshaw, J. M. (2010), What is an adequate sample size? Operationalising data saturation for theory-based interview studies, Psychology and Health, 25(10), 1229-1245.

Guest, G., Bunce, A., and Johnson, L. (2006), How many interviews are enough? An experiment with data saturation and variability, Field methods, 18(1), 59-82. 
Hyväria, I. (2014), Project portfolio management in a company strategy implementation, a case study, Procedia - Social and Behavioral Sciences, 119, 229 - 236

Kaplan, R. S., and Norton, D. P. (2008), The execution premium: Linking strategy to operations for competitive advantage. Boston, USA: Harvard Business Press.

KPMG (2017), Driving Business Performance. Wellington, New Zealand: KPMG.

Lynch, R. L. (2006), Corporate strategy. Harlow, UK: FT/Prentice Hall.

Melton, T., Yates, J., and lles-Smith, P. (2011), Project Benefits Management: Linking projects to the Business. Butterworth-Heinemann.

Meredith, J. R. and Zwikae, O. (2020) Achieving strategic benefits from project investments: Appoint a project owner, Business Horizons, 63(1), 61-71.

Mintzberg, H. (2003), The strategy process: concepts, contexts, cases. Harlow, UK:

Pearson education.

Moore, J. F. (2006), Business ecosystems and the view from the firm, The antitrust bulletin, $51(1), 31-75$.

Morris, P. W. and Pinto, J. K (2004), The Wiley guide to managing projects. Hoboken, NJ: Wiley.

Mossalam, A. and Arafa, M. (2016) The role of project manager in benefits realization management as a project constraint/driver, Housing and Building National Research Centre (HBRC) Journal, 12(3), 305-315.

Opoku, A. and Tallon, A. (2019), The Role of Project Sponsors in Defining and Realising Project Benefits In: Gorse, C and Neilson, C J (Eds) Proceedings of the $35^{\text {th }}$ Annual ARCOM Conference, 2-4 September 2019, Leeds, UK, Association of Researchers in Construction Management, 710-719.

Pellegrinelli, S., and Bowman, C. (1994), Implementing strategy through projects, Long Range Planning, 27(4), 125-132.

PMI (2018), The Pulse of the profession, Project Management Institute (PMI): Philadelphia, PA.

Porter, M. E. (1980), Industry structure and competitive strategy: Keys to profitability. Financial Analysts Journal, 36(4), 30-41.

Porter, M.E., (2001), Strategy and the Internet, Harvard Business Review, 79(3), 62-79.

Quinlan, C., Babin, B. J., Carr, J. C., Griffin, M. and Zikmund, W. G. (2014), Business research methods. Andover, UK: Cengage Learning.

Sense, A. J. (2013), A project sponsor's impact on practice-based learning within projects, International Journal of Project Management, 31(2), 264-271.

Serra, C. E. M., and Kunc, M. (2015), Benefits realisation management and its influence on project success and on the execution of business strategies, International Journal of Project Management, 33(1), 53-66.

Songer, A.D and Molenaar, K.R. (1997), Project Characteristics for Successful Public-Sector Design-Build, Journal of Construction Engineering and Management, 123(1), 34-40

Steyn, J. W. (2019), The elusive project sponsor, Available at: http://www.ownerteamconsult.com/the-elusive-project-sponsor/, Accessed on 19 March 2020.

Tabish, Z.S and Jha, K.N (2011), Identification and evaluation of success factors for public construction projects, Construction Management and Economics, 29(8), 809-823

Turner, D. (2017). Variations of the project sponsor role and benefits realisation: A phenomenographic study, (Unpublished PhD Thesis) Sheffield Hallam University. https://doi.org/10.7190/shu-thesis-00024

Turner, J. R., and Müller, R. (2004), Communication and co-operation on projects between the project owner as principal and the project manager as agent, European Management Journal, 22(3), 327-336.

Winch, G. M., (2010), Managing construction projects. 2nd ed. Oxford: Wiley-Blackwell Publishing.

Winch, G.M., and Leiringer, R. (2016), Owner project capabilities for infrastructure development: A review and development of the "strong owner" concept, International journal of project management, 34(2), 271-281.

Wright, J. N. (1997), Time and budget: the twin imperatives of a project sponsor, International Journal of Project Management, 15(3), 181-186.

Zwikael, O. and Smyrk, J. R. (2011), Project management for the creation of organizational value, London: Springer. 


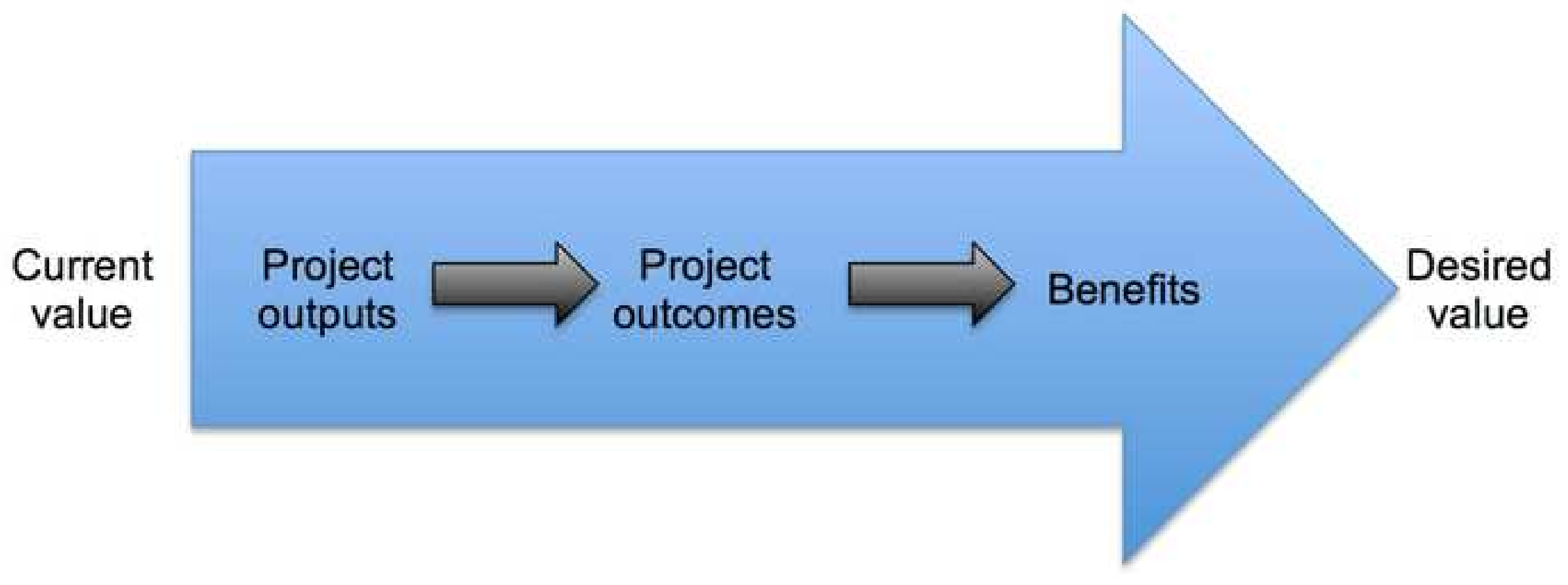




\title{
Realising Project Benefits in the public sector: Project Sponsor's perspective
}

\author{
Alex Opoku ${ }^{1}$, Alexander Tallon ${ }^{2}$, Ka Leung Lok ${ }^{3}$, Charles X. L. Chen ${ }^{4}$ and Tariq Umar ${ }^{5}$ \\ 1,2Bartlett School of Construction and Project Management, University College London, UK \\ ${ }^{3,4}$ Chongqing Business \& Technology University, National Research Base of Intelligent \\ Manufacturing Service, Chongqing, China \\ ${ }^{5}$ College of Engineering, A'Sharqiyah University, Ibra, Oman
}

\section{List of Tables}

Responsibilities of sponsors

1. Define the business benefits/requirements

2. Establishing a project strategy with priorities

3. Agree the project definition, including objectives

4. Define the project success criteria

5. On-going monitoring of the project's business environment and of benefit realisation

6. Taking delivery of a project at completion and, in extreme cases, taking the decision to cancel a project

Table 1: Responsibilities of project sponsors (adapted from Bryde, 2008).

\begin{tabular}{|l|l|l|}
\hline \multicolumn{3}{|l|}{ Sponsor/Owner Project Capabilities } \\
\hline Strategic capabilities & Commercial capabilities & Governance capabilities \\
\hline Project selection & Packaging & Assurance \\
\hline Project mission definition & Contracting & Project coordination \\
\hline Capital raising & Relational & Asset integration \\
\hline Stakeholder managing & & \\
\hline Project portfolio managing & & \\
\hline
\end{tabular}

Table 2: Owner project capability Framework (adapted from Winch and Leiringer, 2016) 


\begin{tabular}{llll}
\hline Interviewee & Role & Type of project & $\begin{array}{l}\text { Years of } \\
\text { experience }\end{array}$ \\
\hline A & Sponsor & Other (Unique project) & $3-4$ \\
B & Principal Sponsor & Highways & $3-4$ \\
C & Principal Sponsor & Highways & $5-10$ \\
D & Sponsor & Highways & $3-4$ \\
E & Sponsor & Other(Unique project) & $3-4$ \\
F & Sponsor & Highways & $3-4$ \\
G & Principal Sponsor & Train Station & $20+$ \\
H & Principal Sponsor & Railway & $3-4$ \\
I & Principal Sponsor & Train Station & $3-4$ \\
J & Principal Sponsor & Train Station & $20+$ \\
K & Sponsor & Railway & $3-4$ \\
L & Principal Sponsor & Railway & $5-10$ \\
M & Principal Sponsor & Railway & $3-4$ \\
N & Sponsor & Other(Unique project) & $3-4$ \\
\hline
\end{tabular}

Table 3: A profile of the interviewees 